\title{
La observancia a nivel judicial, del principio del ne bis in idem y el tratamiento diferenciado, en los requerimientos contra el Estado-demandado (Perú) El apercibimiento por incumplimiento de sentencias judiciales de carácter dinerario
}

\section{The Observance of the Principle of Ne Bis in Idem by the Judiciary and the Differential Treatment in the Requirements against the Respondent State (Peru) The Warning due to Failure to Comply with Judicial Sentences of Monetary Nature}

Edgardo Salomón Jiménez Jara* https://orcid.org/0000-0001-7287-459X http://dx.doi.org/10.21503/lex.v17i24.1811

\footnotetext{
Abogado por la Universidad Nacional Mayor de San Marcos. Egresado de la maestría en Derecho Penal de la Universidad Alas Peruanas. En su desarrollo profesional se ha desempeñado como secretario y relator de Sala Especializada Penal. Magistrado Supernumerario (2007-2010). Procurador público regional (2011-2013). Docente a nivel de pregrado de la Universidad Amazonía de Madre de Dios (UNAMAD) (20112012), Universidad Alas Peruanas - Filial Puerto Maldonado (UAP) (2010-2011) y Universidad Andina del Cusco - Filial Puerto Maldonado (UAC) (2012). Actualmente labora como abogado de asuntos procesales. Perú.

Correo electrónico: salomonu@yahoo.com.
}

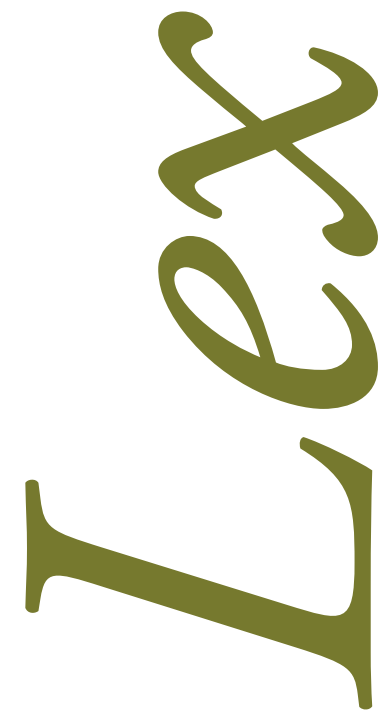




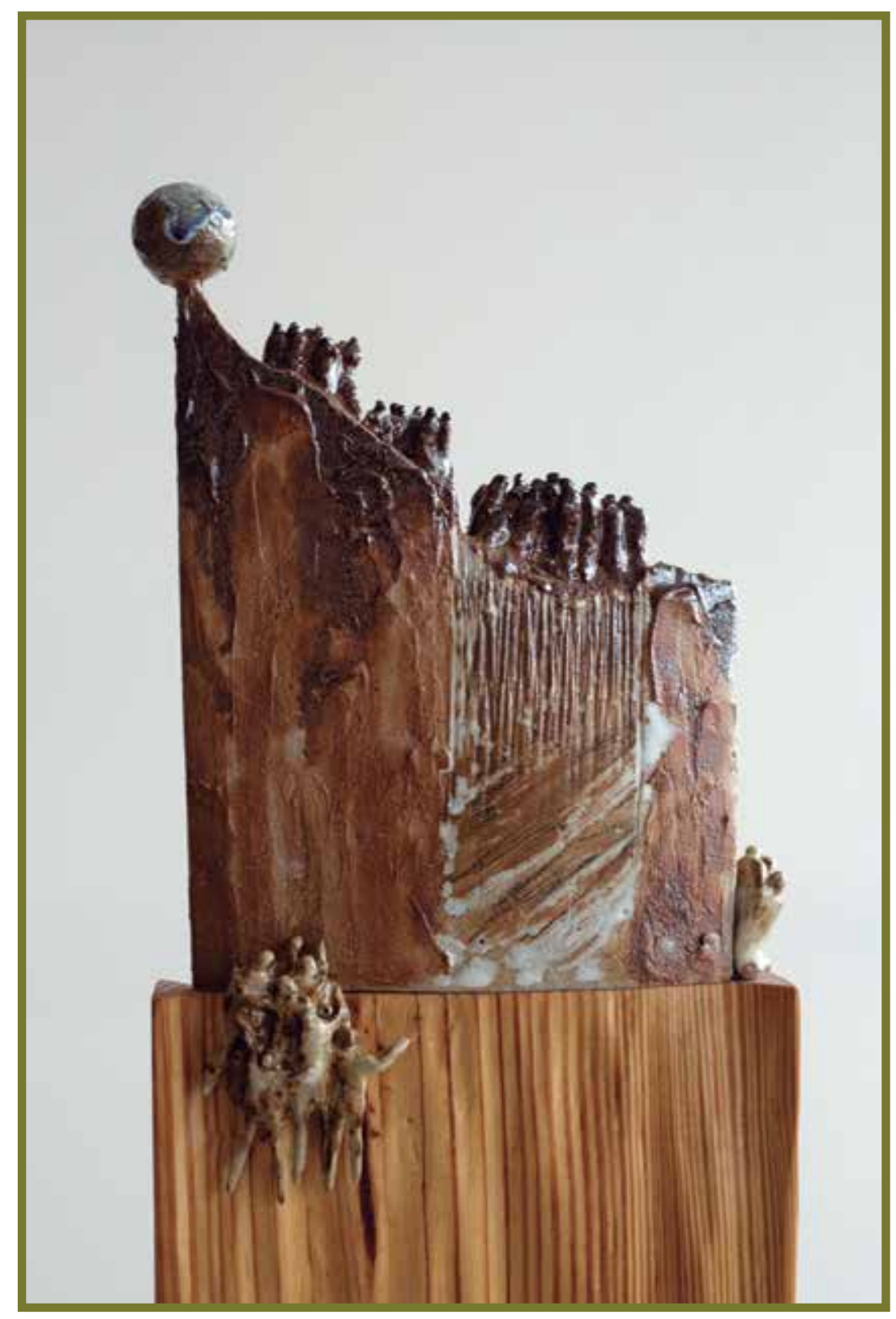

Serie sueños...camino no fácil, 2019.

Cerámica gres y madera, (fragmento) $86 \times 38 \times 40 \mathrm{~cm}$.

Destacado artista plástico nikkei, Oswaldo Higuchi (Perú, 1948) 


\section{RESUMEN}

Las sentencias con calidad de cosa juzgada deben ser cumplidas en sus términos, como una garantía constitucional de la tutela jurisdiccional efectiva. Dentro de las diversas sentencias que se emiten, algunas corresponden a obligaciones dinerarias que deben ser asumidas por el Estado-demandado, contra quien se emite el apremio de multa o de remitir copias al Ministerio Público en caso de incumplimiento. Por ello, a través del presente trabajo abordaremos dichos aspectos vinculados no solo a la obligación del deudor de satisfacer la pretensión del acreedor sino a los apremios que se emiten contra la entidad estatal sea nacional, regional o local, a fin de establecer si dichos requerimientos vulneran garantías constitucionales o se incurre en omisiones al inobservar otras disposiciones vigentes en nuestro ordenamiento jurídico.

Palabras clave: sentencia, tutela jurisdiccional efectiva, presupuesto, facultades, multa.

\section{ABSTRACT}

Firm sentences (called res judicata) must be complied as ruled, as a constitutional guarantee of effective jurisdictional protection. Among the various sentences issued by the judiciary, some correspond to monetary obligations for the State - defendant, against which a fine is issued or the requirement to provide copies to the Public Ministry in case of failure to pay. Therefore, this work addresses such issues not only related to the debtor's obligation to satisfy the creditor's claim but also to the constraints issued against the State entity, whether national, regional or local, in order to establish whether said requirements impair constitutional guarantees or omissions are incurred by incompliance with other provisions in force in our legal system.

Key words: sentence, effective jurisdictional protection, budget, powers, fine. 


\section{INTRODUCCIÓN}

Se advierte, en el extremo referido al cumplimiento de sentencias que contienen una obligación dineraria, que el órgano jurisdiccional en muchas ocasiones, emite requerimientos o apremios en contra del Estado-demandado, de que se le imponga una multa compulsiva y progresiva, o de formularse denuncia penal contra sus funcionarios, en caso no cumpla con el pago del monto dinerario determinado en sentencia, dentro de un plazo - muchas veces breve- que se le otorga.

Por ello, el problema jurídico que ponemos a evaluación es el siguiente:

¿Es posible establecer un apremio de multa o de remitir copias al Ministerio Público contra la entidad o sus funcionarios, en caso se incumpla con el pago de una suma dineraria establecida en una sentencia con calidad de cosa juzgada?

Emplearemos un tipo de investigación cualitativa sustentada en categorías y en un análisis sistemático, dentro de los parámetros de la argumentación jurídica, formulando las conclusiones que correspondan.

Como antecedentes referidos al tema materia del presente trabajo, ponemos a consideración los siguientes:

A nivel internacional, respecto de la eficacia en el cumplimiento de sentencia se ha seńalado:

Deberían establecerse mecanismos lo suficientemente eficaces para evitar violaciones a la tutela judicial efectiva a través del incumplimiento de la sentencia. Para ello es recomendable que se creen normas de ejecución procesal sobre los pasos a seguir al momento en que el juez por omisión, defectuoso entendimiento, pasividad, dilaciones indebidas o cualquier otra forma atente contra la ejecución en sus propios términos. ${ }^{1}$

1 John Romo Loyola, "La ejecución de sentencias en el proceso civil como derecho a la tutela jurisdiccional efectiva” (tesis de maestría, Universidad Internacional de Andalucia, Sede Iberoamericana Santa María de la Rábida, 2001), 104. 
A nivel nacional, respecto de la efectividad de la sentencia contra el Estado se ha seńalado:

El marco jurídico al ser insuficiente no contribuye a que los jueces adopten todas las medidas necesarias y adecuadas tendientes a la efectiva ejecución del fallo; esto es el debido, completo y oportuno cumplimiento de lo resuelto, motivando a que transcurra el tiempo sin que sean atendidos los procesos. Las medidas de coerción, tal como están reguladas actualmente, facilitan a los funcionarios públicos no asumir su responsabilidad a cabalidad; por cuanto solo están dirigidas a ser impuestas contra la entidad y no a la persona (servidor o funcionario). ${ }^{2}$

\section{DE LA SENTENCIA: FACULTADES Y APREMIOS}

La sentencia es el instituto de carácter procesal que contiene la decisión final del juzgador, a la cual arriba en la tramitación de un proceso, donde se ha contrapuesto la posición de ambas partes (demandante y demandado), merituando los medios probatorios ofrecidos y admitidos. Cuando no cabe recurso alguno contra dicha decisión o incluso si en instancia superior ha sido modificada o reformada, adquiere la calidad de cosa juzgada y su cumplimiento es obligatoria para las partes, incluso para terceros.

La sentencia es una resolución judicial con contenido decisorio en donde confluyen dos elementos: a) poner fin a la instancia o al proceso, $y \mathrm{~b}$ ) un pronunciamiento sobre el fondo. Debe entenderse como fondo, un juicio de mérito sobre la pretensión formulada en la demanda, esto es, declararla fundada, fundada en parte o infundada. ${ }^{3}$

\subsection{Clases de sentencia}

Existen diversas clasificaciones de las sentencias, pero solo expondremos las referidas a su contenido, ya que guardan relación con el presente análisis. En ese sentido, las sentencias por su contenido se dividen en las siguientes: ${ }^{4}$

a) Declarativas, al declarar la existencia o inexistencia de un derecho o de un estado jurídico preexistente, sin ir más allá de dicho reconocimiento;

b) Constitutivas, son las que crean, modifican o extinguen un estado jurídico que no preexistía, sino que es totalmente nuevo a partir de la sentencia ejecutoriada; y,

2 María del Pilar Tupiño Salinas, "La efectividad en la ejecución de sentencias contra el Estado por los Juzgados Contencioso Administrativos de la Corte Superior de Justicia de Lima durante el periodo 2003-2015” (tesis para optar el grado de maestra en derecho constitucional, Universidad Nacional Federico Villareal, Escuela Universitaria de Posgrado, 2018), 254.

3 Renzo Cavani, “¿Qué es una resolución judicial? Un breve estudio analítico para el derecho procesal civil peruano”, Ius et Veritas, No 55 (2017).

4 Ricardo Prado Ayau. "La autoejecutividad de las sentencias dictadas por la Corte Interamericana de Derechos Humanos" (tesis doctoral, Universidad del País Vasco, 2018), 108-109. 
c) Condenatorias, aquellas que imponen el cumplimiento de una prestación de dar, hacer, no hacer.

A esto podemos agregar:

d) Mixtas, ya que contienen no solo la declaración o constitución de un derecho, sino que en forma acumulativa disponen el cumplimiento de una prestación. Por ejemplo, las sentencias de naturaleza laboral, donde se reconoce la existencia de una relación laboral y, como consecuencia de ello, se impone el pago de beneficios sociales.

\subsection{Facultades del juzgador}

La norma procesal civil le otorga al juzgador, entre otras facultades, las siguientes:

\subsubsection{Facultades disciplinarias procesales}

Regulado en el art. $52^{\circ}$ del Código Procesal Civil, donde se señala que, a fin de conservar una conducta procesal correspondiente a la importancia y respeto de la actividad judicial, los jueces tienen el deber de:

a. Ordenar que se suprima la frase o palabra expresada o redactada en términos ofensivos o vejatorio. Por ejemplo, cuando en los escritos o en los informes orales se consignen expresiones inadecuadas o agraviantes de una de las partes.

b. Expulsar de las actuaciones a quienes alteren su desarrollo. Si se trata de una de las partes, se le impondrá además los apercibimientos que hubieran sido aplicables de no haber asistido a la actuación. Es el caso en que, en plena audiencia o diligencia programada, una de las partes altera el normal desarrollo de la misma a través de un comportamiento inadecuado.

c. Aplicar las sanciones disciplinarias que este Código y otras normas establezcan. Supuesto que nos remite a otras sanciones de carácter disciplinario que puede aplicar el juzgador y que se encuentran establecidas en la norma procesal civil o similar.

\subsubsection{Facultades coercitivas procesales}

El Código Procesal Civil (art. 53) señala las facultades coercitivas que tiene el juzgador en la tramitación de un proceso regular, la cual está en relación con el fin promovido y buscado en el art. $52^{\circ}$ que a su vez está referido a las facultades disciplinarias, conforme al detalle siguiente:

a. La imposición de multa compulsiva y progresiva destinada a que la parte o quien corresponda, cumpla sus mandatos con arreglo al contenido de su decisión. Por ejemplo, si se ha ordenado suprimir una frase ofensiva, pero la parte infractora es renuente a su 
cumplimiento y la sigue manifestando. En ese supuesto el juzgador tiene la facultad de imponer una multa compulsiva y progresiva hasta que se cumpla con dicho mandato.

Debemos hacer presente que cuando se impone un multa compulsiva y progresiva, implica que el monto impuesto se va incrementando, pero no sumando. Por ejemplo, si se impone una multa de 02 URP y a pesar de ello la parte sigue incumplimiento el mandato, el juzgador la incrementa de manera progresiva en 04 URP. Esto no significa que la multa asciende a $06 \mathrm{URP}$, porque no estamos ante una suma sino una progresión, por lo que la multa asciende a 04 URP.

Dicha multa es establecida de manera discrecional por el juzgador dentro de los límites fijados en el Código Procesal Civil, teniendo la potestad de reajustarla o dejarla sin efecto si considera que la desobediencia ha tenido o tiene justificación.

b. Disponer la detención hasta por 24 horas de quien resiste su mandato sin justificación, produciendo agravio a la parte o a la majestad del servicio de justicia.

Esta potestad es la medida más gravosa, la cual implica la detención o privación de la libertad ambulatoria por espacio de 24 horas. Puede darse en el caso de que un órgano de auxilio judicial se niega a hacer entrega del bien dado en custodia, sin ninguna justificación, existiendo peligro de que huya con el mismo.

El juzgador tiene la potestad, de acuerdo con la importancia y urgencia de su mandato, de la aplicación sucesiva, individual o conjunta de las sanciones antes referidas, con la salvedad de que dichas sanciones se aplicarán sin perjuicio del cumplimiento del mandato

Es pertinente agregar que, si bien dichas facultades disciplinarias se encuentran reguladas en la norma procesal civil, no deben dejarse de lado otras disposiciones de nuestro ordenamiento jurídico que regulan dicho tema, a efectos de entender el contexto de dichas facultades.

Así, el TUO de la Ley Orgánica del Poder Judicial (art. $185.3^{\circ}$ y $185.4^{\circ}$ ) también señala como facultades de los magistrados:

$\checkmark$ Ordenar la detención, hasta por 24 horas, de quienes, en su despacho o con ocasión de las actuaciones judiciales, los injurien, agravien, amenacen o coaccionen por escrito o de palabra, o que promuevan desórdenes, pudiendo denunciar el hecho ante el Ministerio Público.

Se establece el supuesto fáctico de una afectación directa contra el juzgador y la potestad no solo de ordenar la detención sino incluso de formular una denuncia penal. 
Solicitar de cualquier persona, autoridad o entidad pública o privada los informes que consideren pertinentes para el esclarecimiento del proceso bajo su jurisdicción. El incumplimiento al mandato del juez se sanciona con multa no mayor del $5 \%$ de la URP, sin perjuicio de la acción penal que corresponda.

Queda claro que se está refiriendo a una potestad de carácter disciplinario del magistrado mas no a una potestad coercitiva respecto del cumplimiento de una sentencia

\subsection{De la multa}

La multa debe entenderse como una sanción que se aplica como consecuencia de determinada inconducta, previamente establecida como tal, atribuida a alguna de las partes, abogados o apoderados, entre otros.

La multa es una herramienta de importancia para la corrección de conductas, cuyo principal objetivo buscado por la autoridad es disuadir la realización de inconductas, lo que se logra en un análisis costo-beneficio, de tal manera que no resulte más beneficioso realizar la infracción y pagar la multa, que no realizar la infracción. ${ }^{5}$

Podemos distinguir las siguientes clases de multa, de acuerdo a la finalidad que se persigue con su imposición:

a) Multa coercitiva para cumplir un mandato, concebida como una medida de coerción o constreñimiento económico que se impone, previo requerimiento, y se reitera periódicamente, con la finalidad de vencer la resistencia del destinatario del acto a cumplir una decisión. ${ }^{6}$

El fundamento de la multa coercitiva es la advertencia material que se efectúa para convencer al obligado reacio a cumplir con el pago. No se castiga la comisión de una infracción, ni resarcir un dańo producido sino vencer la resistencia del obligado al cumplimiento de su obligación. Se impone una multa pecuniaria, reiterada por lapsos de tiempo que sean suficientes para cumplir lo ordenado. Debemos tener en claro que la multa coercitiva está condicionada a una previa y expresa habilitación contenida en una norma, la cual debe establecer los límites y la frecuencia con la que la Administración puede imponer la multa coercitiva. ${ }^{7}$

5 INDECOPI, "Propuesta metodológica para la determinación de multas en el Indecopi", Documento de Trabajo No 012012/GEE (Lima, abril, 2013): 3.

6 En la Casación N ${ }^{\circ}$ 1502/2017 2018-T.S, Madrid. Fundamento cuarto. Expedida por el Tribunal Supremo de Madrid. Sala de lo Contencioso Administrativo.

7 Víctor Manteca Valdelande, "La multa coercitiva como instrumento de ejecución de las administraciones públicas", Actualidad Administrativa, $\mathrm{N}^{\circ} 4$ (quincena del 16 al 31 de Julio 2011): 1839. 
Si revisamos el TUO de la Ley $\mathrm{N}^{\circ} 27444$ (art. $207^{\circ}$ y $210^{\circ}$ ), se reconoce como una de las formas de ejecución forzada la imposición de multa coercitiva, que es independiente de las sanciones que puedan imponerse con tal carácter y compatible con ellas.

El art. $1^{\circ}$ de las "Normas para la aplicación de multas coercitivas", aprobada por Resolución de Superintendencia N ${ }^{\circ}$ 0014-2018 de la SMV, la regula también como una forma de ejecución forzada:

La multa coercitiva constituye un medio de ejecución forzosa de actos administrativos emitidos por los órganos de la SMV, de conformidad con lo establecido en su Ley Orgánica. Dicha multa se dicta considerando el principio de razonabilidad. La multa coercitiva no constituye una sanción, siendo independiente de las sanciones u otros actos o medidas administrativas que puedan dictarse, por lo que puede ser impuesta dentro o fuera de un procedimiento administrativo sancionador.

Es pertinente agregar que el Código Procesal Constitucional en su art. 22 establece de manera clara medidas coercitivas, como multas fijas y acumulativas, incluso la destitución del funcionario responsable, en caso se incumpla con lo determinado en las sentencias que se emitan y que ordenen la realización de una prestación de dar, hacer o no hacer.

Asimismo, el art. 62 de la Nueva Ley Procesal de Trabajo (Ley 29497) señala la imposición de multa por el incumplimiento injustificado del mandato expedido en un proceso de ejecución, incluso con el apremio de denuncia penal.

b) Multa como sanción administrativa, una manifestación de la potestad sancionadora de la Administración que tiene un fin represivo o retributivo, del que carece la multa coercitiva, por la realización de una conducta anterior y que se encuentra tipificada como falta administrativa. ${ }^{8}$

El "Procedimiento de Cobranza de Multas Impuestas por el Poder Judicial", aprobado por R. A. N N $^{\circ} 59-2016-\mathrm{CE}-\mathrm{PJ}$, define a la multa desde un punto de vista de una multa ya impuesta, sin hacer diferenciación alguna. Es así que señala en su artículo $1^{\circ}$ :

La multa es la sanción pecuniaria impuesta por el Juez —en mérito a las facultades disciplinaria y coercitivas que le otorga el Código Procesal Civil- a los sujetos que intervienen en un proceso judicial, sus abogados y/o terceros, por quebrantar el principio de conducta procesal.

8 En la Casación No 1502/2017 2018-T.S. Madrid. Fundamento cuarto. Expedida por el Tribunal Supremo de Madrid. Sala de lo Contencioso Administrativo. 
La Nueva Ley Procesal de Trabajo (Ley 29497) regula, en sus artículos $15^{\circ}$ y $61^{\circ}$, la imposición de multas, pero de carácter disciplinario, referidas al comportamiento de las partes, testigos o peritos dentro del proceso.

\subsection{De la denuncia penal}

Formular una denuncia penal significa poner en conocimiento de la autoridad competente la ocurrencia de un hecho ilícito, a fin de que se investigue y, si el caso lo amerita, se sancione.

Todo funcionario público está en la obligación de poner en conocimiento los hechos ilícitos que sean de su conocimiento, como consecuencia del ejercicio de sus funciones.

La denuncia es la manifestación que se hace ante el Ministerio Público o la autoridad policial acerca de la realización de ciertos hechos que pueden constituir delito y dar lugar a una acción penal. ${ }^{9}$

Por ejemplo, el art. $564^{\circ}$ del Código Procesal Civil establece el apremio de denuncia por el delito previsto en el art. $371^{\circ}$ del Código Penal (negativa a colaborar con la administración de justicia), en caso se incumpla con emitir un informe del centro de trabajo sobre la remuneración del demandado.

En similar sentido, el art. $441^{\circ}$ del Código Procesal antes referido establece la remisión de copias al Ministerio Público para la investigación del delito, así como la imposición de multa individual no menor de 10 ni mayor de 30 URP, cuando se acredite que el demandante o su apoderado faltaron a la verdad respecto de la dirección domiciliaria del demandado.

Resulta también de observancia lo señalado en el artículo 10.1 del Código Procesal Penal, donde se establece que cuando en la sustanciación de un proceso extrapenal aparezcan indicios de la comisión de un delito de persecución pública, el juez, de oficio o a pedido de parte, comunicará al Ministerio Público para los fines pertinente. Incluso ello puede traer consigo la suspensión del proceso civil, conforme lo regula el artículo $320^{\circ}$ del Código Procesal Civil.

\section{DEL PRINCIPIO DE NE BIS IN IDEM}

Se define el ne bis in idem como: "Nadie puede ser enjuiciado por los mismos hechos que haya sido juzgado por resolución firme en un tribunal penal”, mientras que la definición de non bis in idem significa que "Nadie puede ser juzgado doblemente por un delito". ${ }^{10}$

9 Defensoría del Pueblo, Guía práctica para la denuncia ciudadana contra actos de corrupción y otras faltas contra la ética pública (octubre, 2013).

10 Víctor Lizárraga Guerra, "Fundamento del 'ne bis in idem’ en la potestad sancionadora de la Administración Pública”, $1-11$, acceso el 02 de agosto de 2019,

http://perso.unifr.ch/derechopenal/documentos/articulos\#L 
En ese sentido, se entiende que el ne bis in idem tendría un mayor alcance, pues se refiere de los mismos hechos, mientras tanto en el non bis in idem los alcances son más restrictivos, pues solo se refiere a delitos.

Sobre el ne bis in idem, tenemos los siguientes conceptos:

La Sala Penal Permanente de la Corte Suprema de la República, en el Recurso de Nulidad 873-2016-Nacional, ha señalado que la garantía del ne bis in idem procesal tiene el sentido real de evitar juzgamientos sucesivos o simultáneos por el mismo motivo, siempre que concurran las tres identidades: en la persona, el hecho y el fundamento. Se busca impedir que las autoridades jurisdiccionales sancionen una misma conducta a través de dos procedimientos distintos.

El art. 248.11 del TUO de la Ley $\mathrm{N}^{\circ} 27444$, señala que no se podrán imponer sucesiva o simultáneamente una pena y una sanción administrativa por el mismo hecho en los casos en que se aprecie la identidad del sujeto, hecho y fundamento. Dicha prohibición se extiende también a las sanciones administrativas, salvo la concurrencia del supuesto de continuación de infracciones a que se refiere el inciso 7 .

El art. III del Título Preliminar del Código Procesal Penal refiere que nadie podrá ser procesado, ni sancionado más de una vez por un mismo hecho, siempre que se trate del mismo sujeto y fundamento. Este principio rige para las sanciones penales y administrativas. El derecho penal tiene preeminencia sobre el derecho administrativo.

\section{TRATAMIENTO DIFERENCIADO}

Constituye una garantía constitucional de toda persona, el derecho a la igualdad ante la ley y a no ser discriminado por motivo de origen, raza, sexo, idioma, religión, opinión, condición económica o de cualquiera otra índole (art. 2.2 de la Constitución Política del Estado).

La igualdad como principio constituye la pauta rectora de la organización y actuación del Estado, en general. En cambio, la igualdad como derecho es aquello que obliga tanto a los poderes públicos como a los particulares a actuar uniformemente respecto a las personas que se encuentren en las mismas condiciones o situaciones y a tratar de manera desigual a las personas que se encuentren en circunstancias disímiles, debiendo tener dicho trato dispar un fin legítimo, el mismo que debe ser conseguido mediante la adopción de la medida más idónea, necesaria y proporcional. ${ }^{11}$

11 Víctor García Toma, “El derecho a la igualdad”, Revista Institucional (Academia de la Magistratura) (marzo 2008). 
Agrega dicho autor que:

La diferenciación debe aspirar a una intencionalidad legítima, determinada, concreta y específica. Es decir, deberá asentarse en una justificación objetiva y razonable de acuerdo con certeros juicios de valor generalmente aceptados. En ese sentido, no cabe hablar válidamente de un proceso diferenciador de trato cuando este se basa en supuestos de hecho o situaciones subjetivas. Dicha diferenciación implica una relación efectiva entre el trato desigual que se establece, el supuesto de hecho y la finalidad que se persigue alcanzar.

En igual sentido, se ha pronunciado el Tribunal Constitucional, en el Expediente $\mathrm{N}^{\circ}$ 00437-2014-PA/TC (FJ 08):

La identificación de una diferenciación jurídicamente relevante se realiza mediante la comparación. Ella comporta un análisis del trato que se cuestiona con un objeto, sujeto, situación o relación distintos. Su finalidad es identificar que a supuestos iguales se haya previsto consecuencias jurídicas distintas, o si se ha realizado un trato semejante a situaciones desiguales. En el juicio de igualdad, ese objeto, sujeto, situación o relación con el cual se realiza el contraste, se denomina término de comparación (tertium comparationis).

Es decir, no tomarse en cuenta diferencias pertinentes o bien el otorgamiento de un trato idéntico a personas desiguales es tan discriminatorio como tratar a personas iguales de manera diferente. Como señaló Aristóteles, hay motivo de reclamo "...cuando a los iguales se les otorgan o poseen partes desiguales o a los desiguales partes iguales". ${ }^{12}$

\section{ANÁLISIS}

Ejecutar una sentencia dineraria contra el Estado resulta en muchos casos difícil, ya que esta se regula por una serie de disposiciones presupuestarias o normas especiales. Si bien toda sentencia debe ejecutarse en sus propios términos como una garantía constitucional de la tutela jurisdiccional efectiva, como lo señala Paricio, no se trata de un derecho absoluto y admite excepciones, que se proyectan, por ejemplo en la inembargabilidad de ciertos bienes o en cuanto al procedimiento que debe observarse para su pago, ya que no es posible que el Estado sea tratado como un particular-demandado, toda vez que existen normas específicas que se aplican dentro de la Administración pública, sobre todo lo referido a temas presupuestarios. ${ }^{13}$

El pago de cantidades liquidas, a la cual ha sido condenado la Administración pública (Estado) debe ajustarse a lo establecido en la legislación presupuestaria (principio de legalidad

12 Anne F. Bayefsky, "El principio de igualdad o no discriminación en el derecho internacional", Human Rights Law Journal 11, No 12 (1990).

13 Eduardo Paricio Rallo, "La insolvencia de la Administración. Ejecución judicial", Cuadernos de Derecho Local (QDL) (Fundación Democracia y Gobierno Local), No 30 (2012). 
presupuestaria); es decir, no se pueden realizar pagos si previamente no hay consignación presupuestaria, y esta decisión corresponde en último extremo al Estado condenado, en muchas ocasiones poco dispuesto a abonar el monto que se le exige judicialmente. ${ }^{14}$

En ese sentido, es pertinente tomarse en cuanto los aspectos que a continuación detallamos, al momento de realizar algún requerimiento de pago o apremio contra el Estado-demandado:

\subsection{De la ejecución forzada: inembargabilidad}

El Estado es demandado en procesos sobre obligación de dar suma de dinero o similares, donde se ha determinado que debe cumplir con el pago de una determinada suma dineraria. Dicha obligación se da como consecuencia, por ejemplo, de un proceso donde la pretensión era sobre indemnización por dańos y perjuicios, obligaciones contractuales, entre otras.

La cobranza de la deuda al Estado no solo implica un simple requerimiento, sino que debe observarse otras disposiciones aplicables al caso concreto. Es así que el apremio de ejecución forzada, que alerta sobre un posible remate y adjudicación de un bien mueble o inmueble previamente embargado, debe observar lo referido a la inembargabilidad de bienes del estado.

La inembargabilidad de los bienes patrimoniales del Estado se encontraba regulado en el art. 648.1 del Código Procesal Civil, pero fue declarada inconstitucional por el Tribunal Constitucional (Expediente $\mathrm{N}^{\circ}$ 001-1996-I/TC), precisándose que subsiste la vigencia del artículo $73^{\circ}$ de la Constitución Política del Estado, la cual a su vez señala que son inembargables los bienes del Estado de dominio público.

El Tribunal Constitucional en la sentencia en comento ha señalado que los bienes de dominio público son aquellos en los que el Estado ejerce administración de carácter tuitivo y público, mientras que los de dominio privado son aquellos en que ejerce su propiedad como cualquier persona de derecho privado.

Siendo esto así, la inembargabilidad solo alcanzaría a los bienes de dominio público, por estar vinculados a la administración y finalidad pública que realiza la entidad, como, por ejemplo, bienes inmuebles de propiedad del Estado donde tienen sus sedes las instituciones públicas o cuentas bancarias destinadas a la contratación o pago de una obra pública.

14 José María Agüeras Angulo y Pedro Corvinas Baseca, "La ejecución de sentencias firmes por las entidades locales y su financiación”, Revista Digital CEMCI (Centro de Estudios Municipales y de Cooperación Internacional), No 34 (2017). 


\subsection{De la Ley de Priorización de Pago de Sentencias Judiciales}

Mediante Ley No 30137 y su Reglamento (D.S. 001-2014-JUS), se ha establecido los criterios de priorización para el pago de sentencias judiciales en calidad de cosa juzgada, con el objeto de reducir costos al Estado, en observancia con la sexagésima novena disposición complementaria final de la Ley 29812, Ley de Presupuesto del Sector Público para el Año Fiscal 2012 y en concordancia con lo dispuesto en el artículo $47^{\circ}$ del TUO de la Ley 27584 , aprobado mediante el D.S. 013-2008-JUS, y el artículo $70.1^{\circ}$ del TUO de la Ley 28411, ${ }^{15}$ Ley General del Sistema Nacional de Presupuesto, aprobado mediante el Decreto Supremo 304-2012-EF.

Esta clasificación de los criterios de priorización, conforme se encuentra detallado en la Ley $\mathrm{N}^{\circ} 30137$, su modificatoria dada por Ley $\mathrm{N}^{\circ} 30841$ y su Reglamento, deben consideran el siguiente orden:

Grupo 01: Materia laboral. Obligaciones relativas a derechos individuales o colectivos, originadas con ocasión de la prestación personal de servicios de naturaleza laboral, incluyendo aquellas que se originen en el marco de la intermediación, a través de cooperativas de trabajadores.

Grupo 02: Materia Previsional. Obligaciones vinculadas al acceso a una pensión o al monto de esta, en cualquiera de los sistemas previsionales existentes.

Grupo 03: Víctimas en actos de defensa del Estado y víctimas por violaciones de derechos humanos. Victimas en actos de defensa del Estado: Obligaciones originadas a favor de personal militar de las Fuerzas Armadas y policial de la Policía Nacional del Perú, como producto de acción de armas, actos de servicio, consecuencia del servicio o con ocasión del servicio, de acuerdo con las normas de la materia. Victimas de violaciones de derechos humanos: Obligaciones originadas como producto de los delitos establecidos en el Título XIV-A "Delitos contra la humanidad" del Código Penal, así como las establecidas en sentencias de instancias supranacionales.

Grupo 04: Otras deudas de carácter social. Obligaciones que tengan una o más de las siguientes características: a) Cuyos acreedores o beneficiarios sean personas en situación de

\footnotetext{
15 Art. 70.1 Para el pago de sumas de dinero por efecto de sentencias judiciales en calidad de cosa juzgada, se afecta hasta el cinco por ciento $(5 \%)$ o hasta un mínimo de tres por ciento $(3 \%)$, según sea necesario, de los montos aprobados en el Presupuesto Institucional de Apertura (PIA), con excepción de los fondos públicos correspondientes a las fuentes de financiamiento Donaciones y Transferencias y Operaciones Oficiales de Crédito Interno y Externo, la reserva de contingencia y los gastos vinculados al pago de remuneraciones, pensiones y servicio de tesorería y de deuda. Esta norma comprende, entre otros, la atención de sentencias judiciales en calidad de cosa juzgada por adeudos de beneficios sociales.
} 
pobreza o extrema pobreza según la clasificación socioeconómica establecida en el Sistema de Focalización de Hogares - SISFOH; b) Derivadas de negligencias médicas en centros hospitalarios públicos; c) Cuyos acreedores o beneficiarios tengan alguna discapacidad mental o física grave acreditada por el Consejo Nacional para la Integración de la Persona con Discapacidad - CONADIS, que les impida autosostenerse; d) Los beneficiarios provenientes de la aplicación del artículo 243 del Decreto Legislativo No 398, reglamentado por el Decreto Supremo No 051-88-PCM.

Grupo 05: Deudas no comprendidas en lo grupos previos. Obligaciones que no se encuentran incluidas en los criterios previos. De darse la concurrencia de dos o más criterios, prevalecerá el que más favorezca al acreedor o beneficiario.

En los casos de los grupos 01, 02, 03 y 04 se priorizará el pago a los acreedores mayores de 75 años y/o a los acreedores con enfermedad en fase avanzada y/o terminal, debidamente diagnosticada y acreditada por especialista del Ministerio de Salud y/o EsSalud.

Establecido los grupos, seguidamente se realizará una lista cuyo orden estará determinado por la fecha de notificación de la obligación, iniciando por la más antigua, tomando en cuenta la fecha de notificación del requerimiento de pago, y en el caso de sentencias supranacionales, la fecha de notificación de la sentencia al Estado. En caso de empate entre dos o más obligaciones, se deberá priorizar a los acreedores o beneficiarios de mayor edad, y si a pesar de ello dos o más obligaciones mantuvieran la misma posición, se deberá priorizar a la de menor monto.

Ordenada cada una de las listas, se procederá a priorizar el pago de acuerdo con los montos de las obligaciones, siguiendo para ello los criterios referidos al grupo al cual pertenecen demás aspectos tales como la fecha de notificación, edad de los acreedores y los montos de obligación, en ese orden.

Las deudas se dividirán en 5 niveles de priorización de pago, de la siguiente manera:

* Prioridad A: Menores o iguales a 5 UIT

* Prioridad B: Mayores a 5 hasta 10 UIT

* Prioridad C: Mayores a 10 UIT hasta 20 UIT

* Prioridad D: Mayores a 20 UIT hasta 50 UIT

* Prioridad E: Mayores a 50 UIT 
Establecidos los aspectos antes referidos se formaría una tabla de la forma siguiente

TABLA 1. TABLA CRUZADA

\begin{tabular}{|c|c|c|c|c|c|}
\hline \multirow{2}{*}{$\begin{array}{c}\text { Grupo de deuda por } \\
\text { materia }\end{array}$} & \multicolumn{5}{|c|}{ Prioridad de pago } \\
\cline { 2 - 6 } & A & B & C & D & E \\
\hline Grupo 1 & A1 & B1 & C1 & D1 & E1 \\
\hline Grupo 2 & A2 & B2 & C2 & D2 & E2 \\
\hline Grupo 3 & A3 & B3 & C3 & D3 & E3 \\
\hline Grupo 4 & A4 & B4 & C4 & D4 & E4 \\
\hline Grupo 5 & A5 & B5 & C5 & D5 & E5 \\
\hline
\end{tabular}

Fuente: Ley 30137 y Reglamento.

Es así, que para el cumplimiento de una sentencia que ordena el pago de una suma dineraria por parte del Estado-demandado, debe observarse las normas presupuestarias vigentes en concordancia con la ley de priorización que establece el orden de prelación para el pago de estas. Todo funcionario o servidor público debe observar tales disposiciones en el cumplimiento de los mandatos judiciales a efectos de no favorecerse a uno sobre otros o hacer priorizaciones donde la ley no le otorga tal potestad.

\subsection{Análisis del problema jurídico}

Expusimos al inicio del presente trabajo, la pregunta de si era posible establecer un apremio de multa o de remitir copias al Ministerio Público, contra la entidad o sus funcionarios, ante el incumplimiento del pago de una suma dineraria establecida en una sentencia con calidad de cosa juzgada.

Por lo que pasaremos al análisis respectivo.

\subsubsection{Facultades para imponer multa coercitiva}

El análisis debe partir, en primer término, de las facultades que tiene el juzgador para hacer cumplir sus mandatos.

Es así que lo regulado en el artículo $52^{\circ}$ y $53^{\circ}$ del Código Procesal Civil está referido a las facultades disciplinarias que tiene el juzgador, así como a las acciones coercitivas que puede adoptar para que se cumpla un mandato, dictado en mérito a esas potestades disciplinarias. 
Es pertinente tomar en cuenta Las diferencias que existen entre las medidas disciplinarias y medidas coercitivas. ${ }^{16}$

Las medidas disciplinarias tienen como finalidad disciplinar inconductas de las partes o, mejor dicho, sancionar una indisciplina de las partes a órdenes [interlocutorias] decretadas por el órgano jurisdiccional. Su finalidad es sancionar una inconducta de las partes, ergo, no se orientan a lograr la efectividad de la sentencia.

Las medidas coercitivas o también llamadas medidas psicológicas, tienen por finalidad que se brinde una tutela jurisdiccional efectiva, logrando que se produzca la ejecución efectiva de la sentencia, es decir, lo que se busca es disuadir al ejecutado o crear una presión psicológica en él, para que así cumpla con la sentencia en sus propios términos.

Es decir, sí es posible que se establezcan medidas coercitivas a través de la imposición de una multa, para el cumplimiento de lo ordenado en una sentencia, como extensión del principio de tutela jurisdiccional efectiva, pero para ello, debe estar regulado de manera expresa en la norma procesal civil y en el capítulo pertinente, en estricta observancia del principio de legalidad (previamente señalado como tal) y de tipicidad (descripción expresa de la conducta sancionable).

La labor del juez tiene ciertos límites; es así que en la etapa de ejecución de una sentencia de carácter dinerario debe observarse de manera estricta el principio de iniciativa de parte contenida en el artículo IV del Título Preliminar del Código Procesal Civil, por lo que, frente a un incumplimiento de pago, no puede dictar una medida cautelar de oficio o que no haya sido solicitada por la parte acreedora.

El Capítulo V del Código Procesal Civil señala las potestades que tiene la parte demandante, para ejecutar de manera forzada lo determinado en una sentencia de naturaleza dineraria. Es así que el demandante (acreedor) puede ejecutar, respecto de los bienes muebles o inmuebles afectados previamente con una medida cautelar, el remate y posterior adjudicación de los mismos.

No se encuentra regulado dentro de las facultades del juzgador o del demandante, que se exija el cumplimiento de una sentencia de naturaleza dineraria, con el requerimiento, como medida coercitiva, de imponerse una multa, compulsiva y progresiva, en caso de que se incumpla con la misma.

Esto resulta importante ya que, al tratarse de una medida coercitiva que implica una sanción, debe encontrarse previamente regulado y de manera expresa, como ocurre, por ejemplo,

16 César Muriche Astorayme, "Diferencias entre medidas coercitivas y medidas disciplinarias: a propósito de la detención del gobernador regional de Lambayeque”, La Ley. El Ángulo de la Noticia (2018), acceso el 02 de agosto de 2019,

https://laley.pe/art/6801/diferencias-entre-medidas-coercitivas-y-medidas-disciplinarias-a-proposito-de-la-detenciondel-gobernador-regional-de-lambayeque 
en el TUO de la Ley $\mathrm{N}^{\circ}$ 27444, donde se determina que la multa coercitiva es una de las formas de ejecución forzada de la decisión de la autoridad administrativa. Esto no ocurre en la norma procesal civil.

Tampoco es posible aplicar de manera supletoria lo regulado en la norma procesal constitucional, ya que responde a un tipo de proceso de naturaleza distinta.

Siendo esto así, no resulta válido aplicarse de manera extensiva el apremio de multa coercitiva regulado en el artículo $53^{\circ}$ del Código Procesal Civil, ya que esta responde a una multa coercitiva, pero de naturaleza disciplinaria mas no para el cumplimiento de una sentencia.

\subsubsection{Observancia del principio de legalidad presupuestaria y tratamiento diferenciado}

Otros de los errores en que se incurre, al momento de efectuar un requerimiento de pago, es tratar al Estado-demandado como si fuera un particular que incumple con el pago.

Todo pago que debe realizarse el Estado-demandado debe estar previamente presupuestado, ya que el funcionario no puede tomar un dinero destinado para una finalidad distinta y pagar una deuda de otra naturaleza, puesto que con ello puede incurrir en un ilícito penal.

Cuando se hace referencia a "cumplir con los mandatos judiciales con arreglo al contenido de su decisión”, como supuesto para imponer una multa coercitiva, no es posible hacerlo extensivo a la ejecución de una sentencia de naturaleza dineraria, ya que este extremo tiene un procedimiento propio, donde el tratamiento debe ser diferenciado cuando estamos ante el Estado-demandado.

Como lo ha determinado el Tribunal Constitucional, la aplicación del principio de igualdad no excluye el tratamiento desigual; por ello, no se vulnera dicho principio cuando se establece una diferencia de trato, siempre que se realice sobre bases objetivas y razonables (STC 00009-2007-PI/TC, FJ 20). ${ }^{17}$

En caso del Estado demandado, es objetivamente válido establecer que sus actuaciones deben observar el presupuesto que tiene asignado para cumplir con los pagos; además, es razonable señalar que no tiene la "facilidad" de un particular de pagar al día siguiente el monto adeudado, ya que debe seguir previamente sus procedimientos internos o disposiciones legales aplicables.

\footnotetext{
17 A mayor abundamiento, Huerta señala: "El trato diferenciado debe sustentarse en un objetivo legítimo (principio de razonabilidad). El trato diferenciado debe guardar una relación con el objetivo legítimo que se desea alcanzar (principio de racionalidad). El trato diferenciado debe aplicarse o llevarse a cabo en forma proporcional al objetivo legítimo que se desea alcanzar (principio de proporcionalidad). Luis Alberto Huerta Guerrero, "El derecho a la igualdad", Pensamiento Constitucional 11, No 11 (2005).
} 
No existe disposición expresa en la norma procesal civil que regule el pago de sumas dinerarias cuando el Estado es demandado, por lo que resulta adecuado observar lo regulado en el art. $47^{\circ}$ del TUO de la Ley 27854 Ley del Proceso Contencioso Administrativo, el cual señala que los pagos de obligaciones de sumas de dinero deben ser atendidos por el pliego donde se generó la deuda, incluso bajo responsabilidad del titular, y su cumplimiento se hará de acuerdo a leyes presupuestarias. De superarse las posibilidades de financiamiento, se hará de conocimiento de la autoridad judicial el compromiso de atenderlas en el ejercicio presupuestario siguiente.

Es así que no es posible otorgar un plazo breve de 5 o 10 días para que el Estado- demandado cumpla con el pago, bajo apremio de imponerse multa compulsiva y progresiva. Este tipo de requerimiento vulnera la observancia de normas presupuestarias, ya que no es posible efectuar el pago en tan corto tiempo; además, se considera al Estado-demandado como si fuera un deudor particular, cuando debe realizar un tratamiento diferenciado.

Así, por ejemplo, se ha pronunciado la Sala Penal Permanente en la Casacion N ${ }^{\circ}$ 50-2017/ Piura (2018):

(...) el deber de actuación del funcionario público concernido tiene límites objetivos, no solo en su propio control de la Administración para cumplir la orden judicial —capacidad para dictar órdenes y garantizar la ejecución del mandato judicial—, sino, cuando se trata de recursos públicos, en el respeto a las regulaciones del Derecho Presupuestario. La gestión de los recursos públicos está rigurosamente normativizada, por el cumplimiento de un pago determinado está sujeto a lo que el ordenamiento prevé y a las gestiones que sobre el particular deban hacer las autoridades competentes. (...) debe examinarse cuidadosamente las atribuciones y funciones del agente público concernido, así como — tratándose de fondos públicos- la factibilidad material de su cumplimiento en atención al Derecho administrativo y presupuestario. No se puede exigir lo imposible, ni que se destinen fondos públicos sin la correspondiente autorización legal. (...) El funcionario público no decide libérrimamente sobre fondos públicos y, menos, el desobedecimiento de un mandato judicial puede estimarse delictivo si, al tiempo de su emisión, las reglas presupuestales no lo permiten. La calificación de delictivo de un incumplimiento de un mandato judicial por el solo transcurrir del tiempo no resulta razonable (...).

\subsubsection{Inobservancia del ne bes in idem al remitir copias al Ministerio Público}

Sobre este extremo ponemos a consideración estos aspectos:

a) El supuesto fáctico es el de no cumplir con un mandato judicial, que contiene el pago de una suma de dinero.

b) El denunciado sería el Estado-demandado, o mejor dicho sus funcionarios o servidores. 
c) Apercibimiento (doble), imponerse multa y remitirse copias al Ministerio Público. Como dato concatenado debemos señalar que se está partiendo de un apremio de multa no contemplada de esa forma en la norma procesal civil.

No resulta congruente disponerse la remisión de copias ante el Ministerio Público, contra los funcionarios del demandado acreedor, por cuanto vulneraría la garantía constitucional de que no hay prisión por deudas (art. 2.24.c de la Constitución Política del Estado) y en caso que el acreedor cuente con solvencia económica, debe observarse lo que la norma procesal civil contempla para su ejecución forzada o si se trata del Estado-demandado, observar el principio de legalidad presupuestaria, para el pago de sentencias judiciales con coda juzgada.

Aplicar apremios que no tienen congruencia con lo regulado de la norma procesal civil o en otras normas aplicables determina que se esté imponiendo de manera inadecuada multas fuera del marco legal expreso y generando una carga procesal innecesaria al Ministerio Público, sobre hechos en los cuales previamente debe observarse temas presupuestarios para justamente no incurrirse en ilícitos penales.

Como lo ha señalado el Tribunal Constitucional, el ne bes in idem en su vertiente procesal, significa que "nadie pueda ser juzgado dos veces por los mismos hechos", es decir, que un mismo hecho no pueda ser objeto de dos procesos distintos o, si se quiere, que se inicien dos procesos con el mismo objeto. Con ello se impide, por un lado, la dualidad de procedimientos (por ejemplo, uno de orden administrativo y otro de orden penal) y, por otro, el inicio de un nuevo proceso en cada uno de esos órdenes jurídicos (dos procesos administrativos con el mismo objeto, por ejemplo) (Expediente $N^{\circ}$ 2050-2002-AA/TC-Lima).

Por ello, no es posible que se establezca un doble requerimiento ante el incumplimiento del pago ordenado en una sentencia, ya que vulnera el principio del ne bes in idem ya que se le sanciona a nivel administrativo con la imposición de una multa — de manera inadecuada- y se pretende también una sanción penal sobre ese mismo hecho o supuesto fáctico.

La vulneración del principio del ne bes in idem se advierte al darse el mismo supuesto (no cumplir con el pago de la sentencia) y el requerimiento de imponerse una multa (como sanción) y a la vez considerarse que estamos ante un ilícito penal (sanción penal).

Es pertinente señalar que el Estado-demandado debe ser el primero que debe cumplir con el pago ordenado en una sentencia con calidad de cosa juzgada, por lo que no pretendemos que se incumpla tal obligación, pero para ello debe observarse de manera adecuada el principio de legalidad presupuestaria al momento de realizar los requerimientos contra dicho deudor. 


\section{CONCLUSIONES}

Desarrollados los argumentos antes expuestos, concluimos señalando lo siguiente:

1.1. La diferencia entre la multa coercitiva y la multa como sanción administrativa es que la primera se impone para vencer la resistencia de la parte renuente a cumplir un mandato judicial, durante la etapa de ejecución, mientras que la otra se impone como consecuencia de una infracción o inconducta de carácter disciplinaria, cometida en el desarrollo del proceso.

1.2. El apremio de multa compulsiva y progresiva, contemplada como facultad del juzgador en el artículo $53^{\circ}$ del Código Procesal Civil, no está referido al cumplimiento de un mandato dinerario establecido en una sentencia sino a las facultades disciplinarias que este tiene dentro de un proceso, por lo que no es posible aplicarla de manera extensiva a supuestos distintos.

1.3. Establecer el apremio de imposición de multa y a la vez de denuncia penal, ante el no pago de una suma dineraria por parte del Estado-demandado, establecida en una sentencia con calidad de cosa juzgada, vulnera el principio del ne bes in idem, ya que, al margen de no estar regulado de manera expresa en la norma procesal, se pretende sancionar dos veces por un mismo hecho.

1.4. La ejecución de sentencias de naturaleza dineraria contra el Estado-demandado debe tomar en cuenta el principio de legalidad presupuestaria, así como las normas aplicables al caso en concreto (Ley 30137 y su Reglamento, entre otras), a efectos no solo de observar la norma pertinente, sino que el pago se realice bajo los criterios de priorización previamente establecidos, no favoreciéndose a un deudor sobre otro.

1.5. El tratamiento al Estado-demandado no puede ser la de un deudor particular, ya que estamos ante un caso de tratamiento diferenciado por las normas que rigen a la Administración pública, que regulan la actuación de los funcionarios y servidores públicos. 


\section{REFERENCIAS}

- Agüeras Angulo, José María y Pedro Corvinas Baseca. "La ejecución de sentencias firmes por las entidades locales y su financiación". Revista Digital CEMCI (Centro de Estudios Municipales y de Cooperación Internacional), № 34 (2017): 1-30.

- Bayefsky, Anne F. "El principio de igualdad o no discriminación en el derecho internacional". Human Rights Law Journal 11, No 12 (1990): 1-34.

- Cavani, Renzo. "¿Qué es una resolución judicial? Un breve estudio analítico para el derecho procesal civil peruano". Ius et Veritas, No 55 (2017): 112-127. https://doi.org/10.18800/iusetveritas.201703.007

- Defensoría del Pueblo. Guía práctica para la denuncia ciudadana contra actos de corrupción y otras faltas contra la ética pública (octubre, 2013).

- García Toma, Víctor. "El derecho a la igualdad". Revista Institucional (Academia de la Magistratura) (marzo 2008): 109-127.

- Huerta Guerrero, Luis Alberto. "El derecho a la igualdad". Pensamiento Constitucional 11, No 11 (2005): 307-334.

- INDECOPI. "Propuesta metodológica para la determinación de multas en el Indecopi". Documento de Trabajo No 01-2012/GEE (Lima, abril, 2013).

- Lizárraga Guerra, Víctor. “Fundamento del 'ne bis in idem' en la potestad sancionadora de la Administración Pública”, 1-11. Acceso el 02 de agosto de 2019. http://perso.unifr.ch/derechopenal/documentos/articulos\#L

- Manteca Valdelande, Víctor. "La multa coercitiva como instrumento de ejecución de las administraciones públicas". Actualidad Administrativa, $\mathrm{N}^{\circ} 4$ (quincena del 16 al 31 de julio 2011).

- Muriche Astorayme, César. "Diferencias entre medidas coercitivas y medidas disciplinarias: a propósito de la detención del gobernador regional de Lambayeque". La Ley. El Ángulo de la Noticia (2018). Acceso el 02 de agosto de 2019.

https://laley.pe/art/6801/diferencias-entre-medidas-coercitivas-y-medidas-disciplinarias-aproposito-de-la-detencion-del-gobernador-regional-de-lambayeque

- Paricio Rallo, Eduardo. "La insolvencia de la Administración. Ejecución judicial". Cuadernos de Derecho Local (QDL) (Fundación Democracia y Gobierno Local), No 30 (2012): 119-133. 
- Prado Ayau, Ricardo. "La autoejecutividad de las sentencias dictadas por la Corte Interamericana de Derechos Humanos". Tesis doctoral, Universidad del País Vasco, 2018.

- Romo Loyola, John. "La ejecución de sentencias en el proceso civil como derecho a la tutela jurisdiccional efectiva”. Tesis de maestría. Universidad Internacional de Andalucia, Sede Iberoamericana Santa María de la Rábida, 2001.

- Tupiño Salinas, María del Pilar. "La efectividad en la ejecución de sentencias contra el Estado por los Juzgados Contencioso Administrativos de la Corte Superior de Justicia de Lima durante el periodo 2003-2015”. Tesis para optar el grado de maestra en derecho constitucional. Universidad Nacional Federico Villareal, Escuela Universitaria de Posgrado, 2018.

RECIBIDO: 02/08/19

APROBADO: $12 / 11 / 19$ 


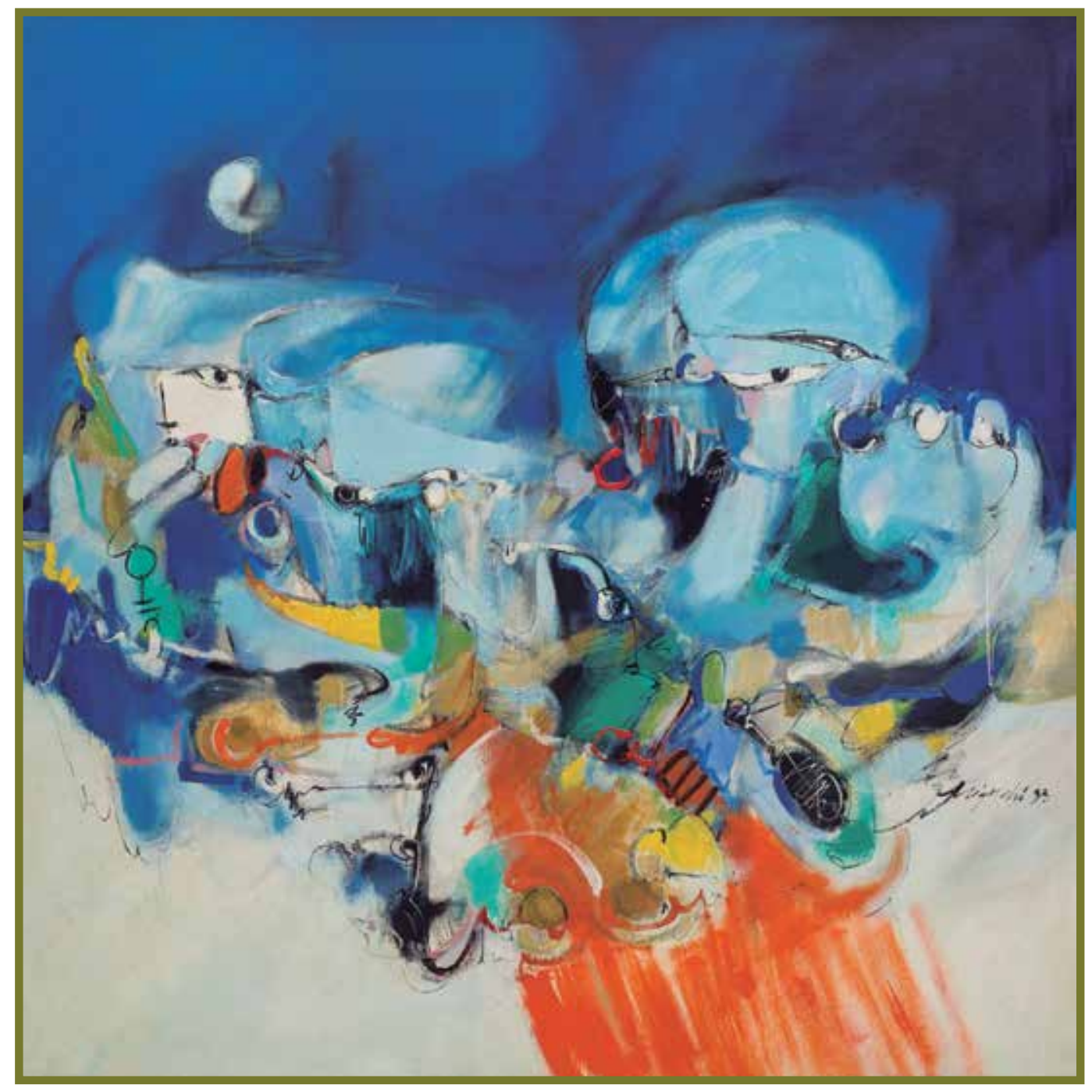

Mirar cotidiano, 1991. Acrílico sobre tela, 48 x $50 \mathrm{~cm}$.

Destacado artista plástico nikkei, Oswaldo Higuchi (Perú, 1948) 